\title{
Erratum to: Obtaining the surface PGA from site response analyses based on globally recorded ground motions and matching with the codal values
}

\author{
${\text { Abhishek } \text { Kumar }^{1} \text { (D) Olympa Baro }}^{1}$ - N. H. Harinarayan ${ }^{1}$
}

Published online: 29 June 2016

(C) Springer Science+Business Media Dordrecht 2016

\section{Erratum to: Nat Hazards (2016) 81:543-572 \\ DOI 10.1007/s11069-015-2095-x}

An error was introduced during the preparation of Fig. 2: the labels of two vertical axes were interchanged. The corrected figure (Fig. 2) is displayed here.

The online version of the original article can be found under doi:10.1007/s11069-015-2095-x.

Abhishek Kumar

abhitoaashu@gmail.com; abhiak@iitg.ernet.in

1 Department of Civil Engineering, Indian Institute of Technology, Guwahati, India 


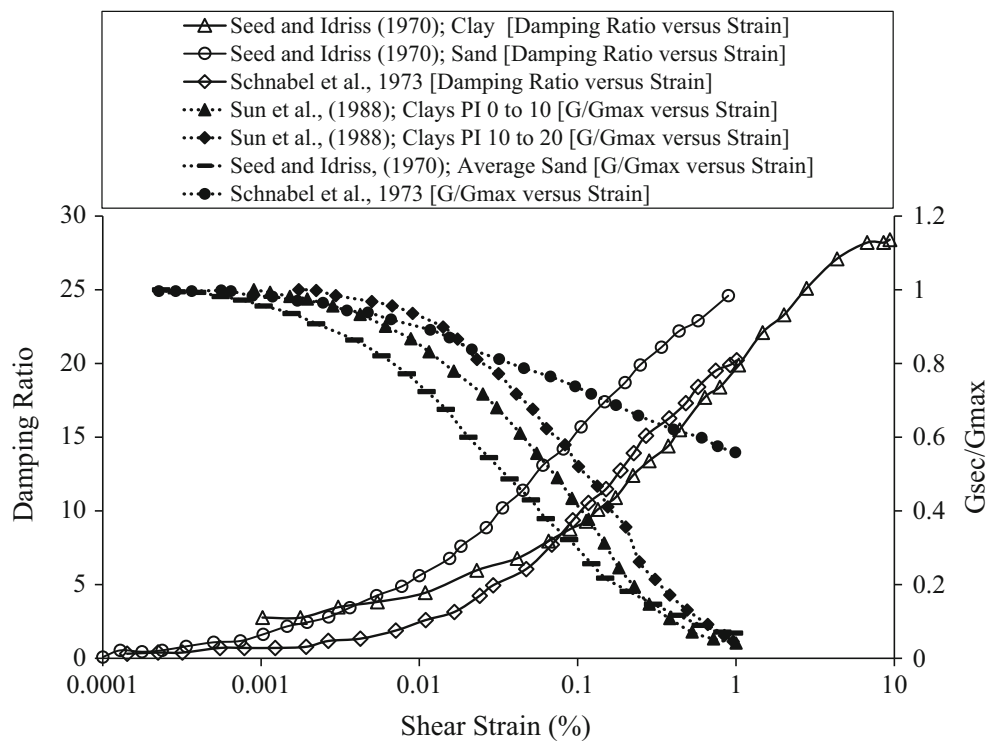

Fig. 2 Dynamic properties of selected soils 